WellBeing International

WBI Studies Repository

$9-2003$

\title{
Social Learning of Prey Location in Hatchery-Reared Atlantic Salmon
}

C. Brown

University of Cambridge

A. Markula

University of Cambridge

K. Laland

University of Cambridge

Follow this and additional works at: https://www.wellbeingintlstudiesrepository.org/acwp_aff

Part of the Animal Studies Commons, Comparative Psychology Commons, and the Other Animal Sciences Commons

\section{Recommended Citation}

Brown, C., Markula, A., \& Laland, K. (2003). Social learning of prey location in hatchery-reared Atlantic salmon. Journal of Fish Biology, 63(3), 738-745.

This material is brought to you for free and open access by WellBeing International. It has been accepted for inclusion by an authorized administrator of the WBI Studies Repository. For more information, please contact wbisr-info@wellbeingintl.org.

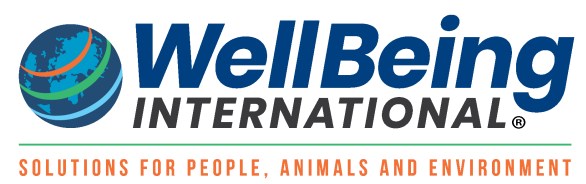




\title{
Social Learning of Prey Location in Hatchery- Reared Atlantic Salmon
}

\author{
C. Brown, A. Markula and K. Laland \\ University of Cambridge
}

\section{KEYWORDS}

Atlantic salmon, benthos, hatchery, prey location, social learning

\begin{abstract}
Naïve, hatchery-reared Atlantic salmon Salmo salar parr were paired with demonstrators that had been pre-trained to accept live prey from the surface or from the benthos. After 6 days of observing demonstrators through a clear perspex partition the naïve fish's benthic foraging skills were tested. The results revealed that hatchery-reared Atlantic salmon can be taught to target benthic prey items by observation alone and social learning protocols can be utilized to dramatically increase benthic foraging success. The results are discussed with reference to refining hatchery-rearing practices with a view to improving the post-release survival of hatchery fishes. The role of learning, and in particular social learning, in the development foraging behaviour is highlighted.
\end{abstract}

\section{INTRODUCTION}

Hatchery-reared fishes are increasingly used to enhance wild populations that suffer from overexploitation. Fishes released from hatcheries, however, suffer from high post-release mortality, which fisheries scientists and hatchery managers have been aware of for well over a century (Brown \& Laland, 2001). It has only been relatively recently that deficits in the behaviour of hatchery fishes were identified as the principal cause of this mortality. Both foraging and predator evasion behaviour are poorly developed in hatchery fishes (Brown \& Day, 2002; Brown \& Laland, 2002). As these behaviour patterns are partly dependent on experience to develop (Kieffer \& Colgan, 1992) it is highly likely that the behavioural deficits exhibited by hatchery fishes stem from the unnatural circumstances in which they are raised, and from the absence of the opportunity to learn relevant life skills (Brown \& Laland, 2001). In a foraging context, learning enables individuals to improve their prey recognition, attack mode and handling efficiency. This behavioural flexibility is especially important when foraging in the wild where the distribution, abundance and trophic value of prey are variable (Hughes et al., 1992). It is now well established that prior exposure to live prey increases the foraging success of fishes (Paszkowski \& Olla, 1985; Stradmeyer \& Thorpe, 1987; Reiriz et al., 1998; Ellis et al., 2002).

Early attempts to raise enough wild prey to maintain hatchery populations proved difficult so the focus of hatchery research quickly turned to developing artificial food sources (Embody \& Gordon, 1924). Today, nearly all hatchery fishes are routinely reared on manufactured pellet foods that require limited use of the fish's potentially extensive foraging repertoire. Food is routinely added to the surface of enclosures and 
there is no variation in the timing, location, abundance or type of food on offer. As a consequence, there is evidence that inappropriate search images or foraging strategies are conditioned during the early stages of development in the hatchery (Ware, 1971; Sosiak et al., 1979; Coughlin, 1991; Langley, 1996; Ellis \& Nash, 1998; Reiriz et al., 1998).

Starvation is often cited as one of the principal causes of mortality in fishes released from hatcheries (Paszkowski \& Olla, 1985). Indeed starvation in the 'midst of plenty' has often been observed (Suboski \& Templeton, 1989). Following release from the hatchery many fishes may not eat for several days, weeks or months (Miller, 1954; Paszkowski \& Olla, 1985; Usher et al., 1991). When they do start to forage they typically take up high risk and energetically costly positions close to the surface of the water [e.g. red drum Sciaenops ocullatus (L.); Stunz et al., 2001]. This behaviour not only exposes them to higher water velocities and predation pressure, but also reduces contact with potential benthic prey items (Olla et al., 1998). Consequently, hatchery fishes also show limited prey choice, take fewer items and are very slow to switch between prey types compared with wild fishes (Sosiak et al., 1979; Ersbak \& Haase, 1983). Hatchery fishes show substantial mass loss following release and their mortality rates can be up to ten times greater compared to transplanted wild fishes (Miller, 1954).

There has been much discussion of the possibility that the viability of hatchery fishes could be enhanced by some form of training prior to release to help them recognize potential predators and prey items (Brown \& Day, 2002). There is now considerable evidence that the rate of learning can be increased by applying social learning protocols to fishes (Suboski \& Templeton, 1989; Brown \& Laland, 2001, 2002). Social learning occurs when naïve individuals learn by observing or interacting with others. A previous study suggested that foraging individuals may provide a cue to naïve conspecifics as to the location of prey items (Brown \& Laland, 2002). When Atlantic salmon Salmo salar L. strike at prey items and return to their foraging stations, they may provide information regarding prey location to surrounding conspecifics. The aim of the present study was to examine if the direction of the strike provides information about the location of available prey by exposing naïve Atlantic salmon parr (observers) to conspecifics that had been pre-trained to strike at prey items on the benthos (demonstrators). The foraging behaviour of these observer fish was compared to control individuals who had only observed demonstrators striking at the surface.

\section{METHODS}

Subjects were allocated to one of two conditions in which they either observed real demonstrators trained to eat food delivered to the benthos (test condition) or sham demonstrators that fed at the surface (control condition). Subsequently, subjects were tested to ascertain their proficiency at benthos feeding by recording their latency to feed and number of food items consumed.

\section{SUBJECTS AND APPARATUS}

Three-hundred hatchery-reared Atlantic salmon parr were obtained from the Environment Agency hatchery at Kielder, Northumbria, U.K. On arrival at the University of Cambridge the fish were placed into four holding tanks. These holding tanks consisted of 2271, round, black plastic tubs, each containing $\mathrm{c}$. 75 conspecifics and designed to simulate hatchery conditions. The holding tanks were connected to a recirculating, biological filter system. Prior to the experiment the fish were maintained on the same pellet diet as at the hatchery. Room temperature was kept at $14^{\circ} \mathrm{C}$ and overhead fluorescent globes maintained at $12 \mathrm{~L}: 12 \mathrm{D}$ photoperiod. The fish were c. 12 months of age at the time of experimentation.

The test tanks in which the experiments took place consisted of six $1 \mathrm{~m}$ aquaria that had been divided into thirds by black opaque barriers. Each of these three compartments were divided in half again by a $2 \mathrm{~mm}$ 
sheet of clear perspex. Therefore each individual compartment was $15 \mathrm{~cm}$ wide and $30 \mathrm{~cm}$ long. Water depth was maintained at $180 \mathrm{~mm}$. The test tanks were surrounded by black plastic on three sides and a black plastic hide was present on the fourth side allowing the experimenter to observe and record the behaviour of the fish without disturbing them. Half of the top of the tank closest to the hide was also covered with black plastic. This cover had a small hole punched through it allowing the experimenter to deliver prey items using a pipette. The remaining open half allowed light to enter the tanks. Each compartment was also equipped with a feeding apparatus consisting of a length of round electrical conduit pipe (30 cm length $20 \mathrm{~mm}$ diameter) mounted vertically in the tank (Fig. 1). The pipe stood in the corner closest to the hide and the clear partition in each compartment. Half of the bottom end of the pipe had been sawn off both to support the pipe on the bottom of the compartment but also to shield the appearance of the prey from the neighbouring compartment. The top end of the pipe emerged from the top of the hide to allow the prey items to be placed into the pipe without disturbing the fish. The prey items sank down the length of the tube out of sight of the fish and emerged at the bottom.

Each of the test tanks was placed on white polystyrene. Since Atlantic salmon generally prefer to hold station on dark surfaces from which they strike at prey items and quickly return, a black strip of plastic 5 $\mathrm{cm}$ wide was placed under the tanks running along the length of the tanks farthest from the hide. This black strip not only served to control the location of the fish throughout the experiment, but also enabled them to settle into the new environment more quickly.

\section{PROCEDURE}

Nine fish were taken at random from the holding tanks, designated as 'benthos' demonstrators and placed on one side of the clear partitions in the test tanks. Demonstrator fish were pre-trained to accept prey items (frozen bloodworms, Chironomid spp.) that emerged from the bottom of the pipe. There were two training sessions per day, one in the morning (c. 0900 hours) and one in the evening (c. 1900 hours). During a training session three prey items were placed into the feeding pipe, one at a time and at an interval of $30 \mathrm{~s}$. These prey items emerged at the bottom of the tube and were available to the demonstrators to consume. By the end of the third day of training (i.e. after six exposures) all demonstrators readily accepted prey items from the bottom of the pipe. A further nine 'surface' demonstrators were chosen at random and were fed via a pipette at the surface of the water at the same time as the real demonstrators.

Following the training of the demonstrators, 18 naïve conspecifics (benthos and surface observers) were added to the other side of the clear partitions in the test tanks. Twice a day for 5 days the benthos demonstrators were fed three prey items via the pipe that delivered the prey to the benthos and the surface demonstrators were fed via pipette at the surface. The observers could watch the demonstrators feeding through the clear partition. Directly following the feeding of the demonstrators their corresponding observers were fed by pipette at the surface only. After the final feed on the evening of the fifth day the demonstrators were removed. The next morning all the observers were fed (via the pipe) on the benthos and the mean time to consume the prey was recorded. Fish that failed to consume the prey item in $<5$ min were allocated a ceiling value of $300 \mathrm{~s}$. Due to limitations on the number of fish tanks available the experiment was repeated using the same apparatus but with new fish. In total 18 surface observers and 18 benthos observers were tested. The latency data were log10 transformed and analysed using an ANOVA. The number of observers successfully foraging on the benthic prey items was compared using a $x^{2}$-test.

The reverse test examining strike latency at the surface was not performed since hatchery-reared Atlantic salmon have a strong tendency to strike preferentially at prey items on the surface. On the last day of training all fish accepted bloodworms at the surface, however, data were only collected for the first nine 
replicates. On the last day of training control fish displayed a mean \pm s.E. Strike latency of $2.66 \pm 1.09 \mathrm{~S}$ and test fish had a strike latency of $3.00 \pm 0.93 \mathrm{~s}$ (ANOVA, d.f. $=1$ and $14, P=0.878$ ).

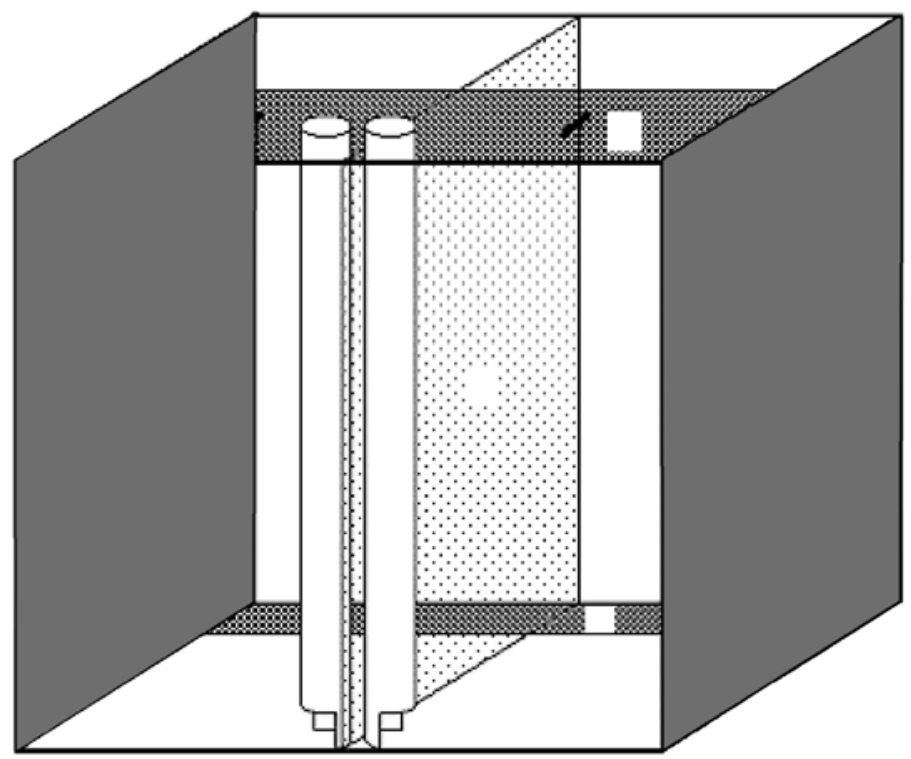

FIG. 1. A diagrammatic view of a pair of compartments divided by a sheet of clear Perspex (1). A demonstrator was placed on one side of the partition and its observer on the other. The apparatus was designed to deliver the prey items to the benthos (upright tube; 2 ). The top of the compartments was covered by another sheet of black plastic and had a hole cut in it (3) through which prey items could be delivered to the surface by a pipette. The black plastic strip (4) underneath the tank is evident in the background.

\section{RESULTS}

As expected all the fish spent the majority of their time in the back section of the test tanks on top of the black plastic strip provided (Fig. 1). During the training sessions, surface demonstrators attacked a bloodworm soon after it hit the surface of the water and returned to the black strip. Bloodworms delivered to the benthos were less conspicuous, nevertheless, all benthos demonstrators found the prey item on every occasion and provided clear demonstration to their observers. Fourteen of the $18(78 \%)$ observers trained with benthos demonstrators (test fish) discovered the prey items on the benthos within the time limit. Whereas only eight of the $18(44 \%)$ observers trained with surface demonstrators (control fish) accepted the bloodworms from the benthos $\left(x^{2}, \mathrm{~d} . \mathrm{f}=1, P<0 \cdot 005\right)$.

The latency to strike the bloodworm on benthos was significantly faster for benthos fish than for surface fish (ANOVA on $\log _{10}$ values; d.f. $=1$ and 34, $P=0.0172$ ). Benthos fish took a mean \pm s.E. of $91.8 \pm 30.3 \mathrm{~s}$ to discover the prey item whereas surface fish took $189.6 \pm 29.5 \mathrm{~s}$ (Fig. 2).

\section{DISCUSSION}

It is well established that many fishes forage more efficiently in social groups than alone or in small groups (Pitcher \& House, 1987; Ryer \& Olla, 1991; Sundstrom \& Johnsson, 2001). Firstly, as group size increases the probability that a fish will discover a food resource also increases. Once found the foraging behaviour of the successful individual provides a cue to the rest of the group as to the location (forage 
area copying) or even content of the foraging patch. Secondly, as group size increases individuals spend less time scanning for predators and more time searching for food (Pitcher \& Parish, 1993). Godin (1978) observed that once a few juvenile pink salmon Oncorhynchus gorbuscha (Walbaum) had started to feed on a novel live prey item 'Artemia salina' the remainder of the group was attracted to the area and also started to feed. This 'swarm feeding' is often observed in hatchery situations where fish density is many times higher than in the wild. Thus, social learning enables the rapid spread of information through a population and many individuals subsequently discover the resource much quicker than they would have if they had searched on their own (Brown \& Laland, 2001). A previous study investigating social learning of foraging behaviour in Atlantic salmon suggested that the direction of the strike made by demonstrators at prey items not only provides a cue that food is available but may also contain some information regarding its location (Brown \& Laland, 2002). The results herein certainly support that notion. Fish that had observed demonstrators striking at prey items on the benthos were more likely to strike at the benthic prey items and did so more quickly than fish that had been exposed to demonstrators feeding at the surface. The prey items used in this experiment (chironomid larvae) are usually found in the benthos and so benthic feeding in this context is particularly relevant.

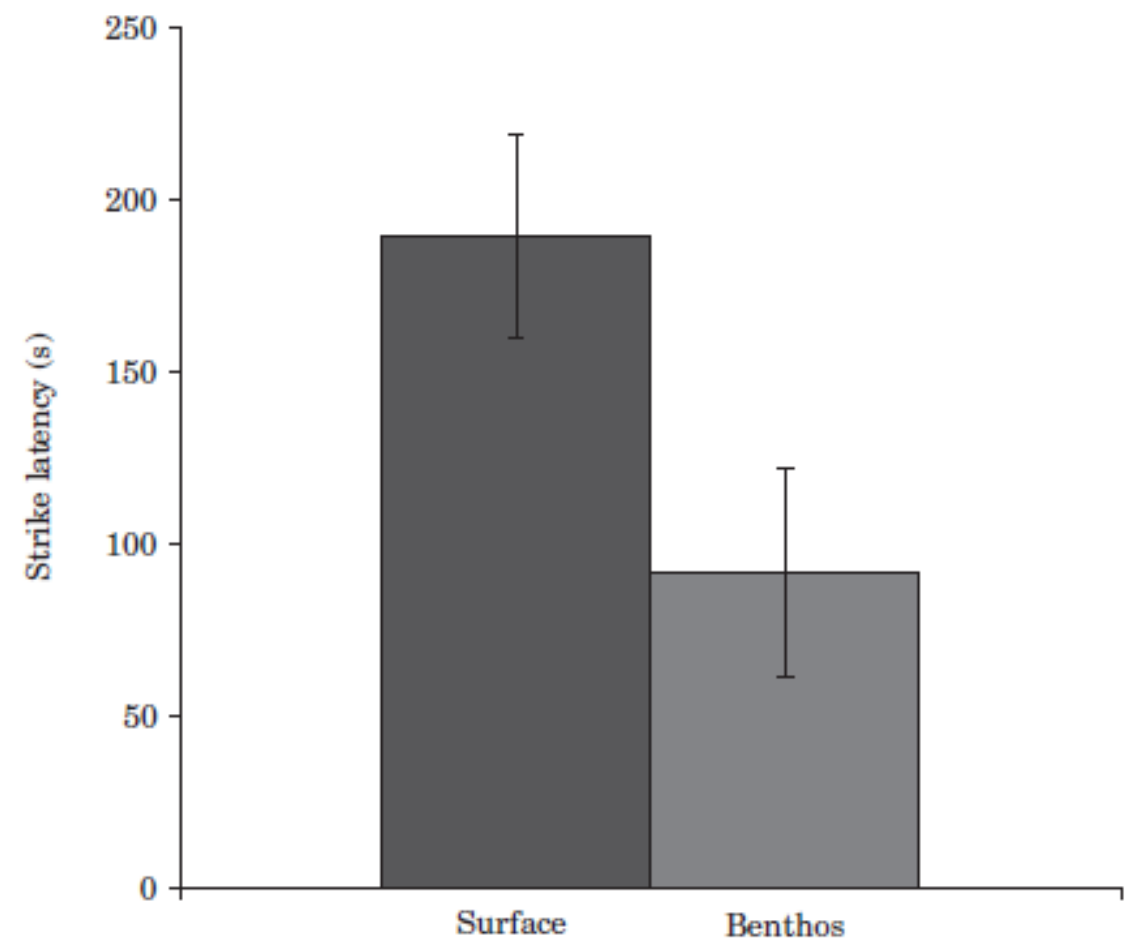

FIG. 2. Mean \pm S.E. strike latency at live prey on the benthos by observer fish with surface demonstrators (control condition) and fish with benthos demonstrators (test condition). Test fish took a mean of $91.8 \mathrm{~s}$ to strike at the prey item whereas control fish took $189.6 \mathrm{~s}(P=0.0172)$

Hatchery-reared fishes often possess a preference for taking prey from the surface (Nislow et al., 1998; Reinhardt, 2001), even when this behaviour may not be part of their natural foraging repertoire (Furuta, 1996). This preference is brought about by frequent and long-term conditioning in the hatchery environment and may be detrimental following release (Stunz et al., 2001). Hatchery-reared Japanese flounder Paralichthys olivaceus (Temminck \& Schlegel), for example, are fed at the surface which induces 
an unnaturally high level of 'off the bottom swimming activity' post-release, thus increasing their susceptibility to predators (Furuta, 1996). The results of the present experiment show that not only can the fish be rapidly trained to accept prey items from the benthos, but exposure to more knowledgeable conspecifics dramatically increases benthic feeding success. Reduced surface feeding may, in some cases, also reduce predator-mediated mortality by encouraging fish to take up more appropriate feeding stations closer to the bottom of the water column. Many hatchery-reared fishes show a much narrower diet than their wild counterparts and the number of benthic prey items represented is particularly depauperate (Olla et al., 1998; Brown \& Laland, 2001). The results of the present study suggest that prior exposure to benthic prey items, particularly in the presence of pre-trained conspecifics, would increase the number of benthic prey items included in the diet post-release.

Whilst these experiments were only conducted on a small scale compared to the types of procedures required at a hatchery level, it is apparent that hatcheries should reconsider the manner in which food is delivered and the variety of prey items offered to hatchery fishes. Brown \& Day (2002) recently suggested that the addition of live prey items for a brief period just prior to release could make a significant difference to the post-release survival of hatchery-reared fishes. Turbot Scopthalmus maximus (L.), for example, appear to remember the visual characteristics of live prey for at least 6 weeks (Ellis et al., 2002) providing further support for training regimes involving exposure of hatchery fishes to live prey in the weeks prior to release. Furthermore, exposure to one type of live prey enables hatchery-reared fishes to generalize to other types of live prey (Brown et al., 2003) and thus prior exposure to live prey ought to significantly broaden the diet of hatchery fishes post-release. While most of the empirical data available support this theory, large-scale tag recapture studies are required before the benefits of such a scheme can be properly scrutinized. From an economic perspective the added cost of feeding live prey to hatchery-reared fishes just prior to release would have to be weighed up against any perceivable increase in post-release survival.

This work was funded by BBSRC grant 8/S15529. KNL was supported by a Royal Society University Research Fellowship. We are grateful to the Environment Agency hatchery at Kielder for providing the salmon.

\section{References}

Brown, C. \& Day, R. (2002). The future of stock enhancements: lessons for hatchery practice from conservation biology. Fish and Fisheries 3, 79-94.

Brown, C. \& Laland, K. N. (2001). Social learning and life skills training for hatchery reared fish. Journal of Fish Biology 59, 471-493. doi: 10.1006/jfbi.2001.1689.

Brown, C. \& Laland, K. (2002). Social learning and social inhibition of foraging behaviour in hatcheryreared Atlantic salmon. Journal of Fish Biology 61, 987-998. doi: 10.1006/jfbi.2002.2114.

Brown, C., Davidson, T. \& Laland, K. (2003). Environmental enrichment and prior experience of live prey improve foraging behaviour in hatchery-reared Atlantic salmon. Journal of Fish Biology 63 (Suppl. A).

Coughlin, D. J. (1991). Ontogeny of feeding-behavior of 1st-feeding Atlantic salmon (Salmo salar). Canadian Journal of Fisheries and Aquatic Sciences 48, 1896-1904.

Ellis, T. \& Nash, R. D. M. (1998). Predation on wild 0-group flatfishes by released and wild turbot, Scopthalmus maximus. In Stocking and Introduction of Fish (Cowx, I. G., ed.), pp. 319-326. Oxford: Blackwell Science. 
Ellis, T., Hughes, R. N. \& Howell, B. R. (2002). Artificial dietary regime may impair subsequent foraging behaviour of hatchery-reared turbot released into the natural environment. Journal of Fish Biology 61, 252-264. doi: 10.1006/jfbi.2002.2041.

Embody, G. C. \& Gordon, M. (1924). A comparative study of natural and artificial foods of brook trout. Transactions of the American Fisheries Society 64, 185-200.

Ersbak, K. \& Haase, B. (1983). Nutritional deprivation after stocking as a possible mechanism leading to mortality in stream-stocked brook trout. North American Journal of Fisheries Management 3, 142-151.

Furuta, S. (1996). Predation of juvenile Japanese flounder (Paralichthys olivaceus) by diurnal piscivorous fish: field observations and laboratory experiments. In Survival Strategies in Early Life Stages of Marine Resources (Watanabe, Y., Yamashita, Y. \& Oozeki, Y., eds), pp. 285-294. Rotterdam: A.A. Balkema.

Godin, J. G. J. (1978). Behaviour of juvenile pink salmon (Oncorhynchus gorbuscha Walbaum) toward novel prey: influence of ontogeny and experience. Environmental Biology of Fishes 3, 261-266.

Hughes, R. N., Kaiser, M. J., Mackney, P. A. \& Warburton, K. (1992). Optimizing foraging behaviour through learning. Journal of Fish Biology 41 (Suppl. B), 77-91.

Kieffer, J. D. \& Colgan, P. W. (1992). The role of learning in fish behaviour. Reviews in Fish Biology and Fisheries 2, 125-143.

Langley, C. M. (1996). Search images: Selective attention to specific visual features of prey. Journal of Experimental Psychology-Animal Behavior Processes 22, 152-163.

Miller, R. B. (1954). Comparative survival of wild and hatchery-reared cutthroat trout in a stream. Transactions of the American Fisheries Society 83, 120-130.

Nislow, K. H., Folt, C. \& Seandel, M. (1998). Food and foraging behavior in relation to microhabitat use and survival of age-0 Atlantic salmon. Canadian Journal of Fisheries and Aquatic Sciences 55, 116-127.

Olla, B. L., Davis, M. W. \& Ryer, C. H. (1998). Understanding how the hatchery environment represses or promotes the development of behavioral survival skills. Bulletin of Marine Science 62, 531-550.

Paszkowski, C. \& Olla, B. (1985). Foraging behaviour of hatchery produced coho salmon (Oncorhynchus kisutch) smolts on live prey. Canadian Journal of Fisheries and Aquatic Sciences 42, 1915-1921.

Pitcher, T. J. \& House, A. (1987). Foraging rules for group feeders: area copying depends upon density in shoaling goldfish. Ethology 76, 161-167.

Pitcher, T. J. \& Parish, J. (1993). The function of shoaling behaviour. In The Behaviour of Teleost Fishes, 2nd edn. (Pitcher, T. J., ed.), pp. 363-439. London: Chapman \& Hall.

Reinhardt, U. G. (2001). Selection for surface feeding in farmed and sea-ranched masu salmon juveniles. Transactions of the American Fisheries Society 130, 155-158.

Reiriz, L., Nicieza, A. G. \& Brana, F. (1998). Prey selection by experienced and naïve juvenile Atlantic salmon. Journal of Fish Biology 53, 100-114.

Ryer, C. H. \& Olla, B. L. (1991). Information transfer and the facilitation and inhibition of feeding in a shoaling fish. Environmental Biology of Fishes 30, 317-323.

Sosiak, A., Randall, R. \& McKenzie, J. A. (1979). Feeding by hatchery-reared and wild Atlantic salmon (Salmo salar) parr in streams. Journal of the Fisheries Research Board of Canada 36, 14081412.

Stradmeyer, L. \& Thorpe, J. (1987). Feeding behaviour of wild Atlantic salmon, Salmo salar L., parr in mid- to late summer in a Scottish river. Aquaculture and Fisheries Management 18, 33-49.

Stunz, G. W., Levin, P. S. \& Minello, T. J. (2001). Selection of estuarine nursery habitats by wild-caught and hatchery-reared juvenile red drum in laboratory mesocosms. Environmental Biology of Fishes 61, 305-313.

Suboski, M. D. \& Templeton, J. J. (1989). Life skills training for hatchery fish: Social learning and survival. Fisheries Research 7, 343-352. 
Sundstrom, L. F. \& Johnsson, J. I. (2001). Experience and social environment influence the ability of young brown trout to forage on live novel prey. Animal Behaviour 61, 249-255.

Usher, M. L., Talbot, C. \& Eddy, F. B. (1991). Effects of transfer to seawater on growth and feeding in Atlantic salmon smolts (Salmo salar L). Aquaculture 94, 309-326.

Ware, D. M. (1971). Predation by trout (Salmo gairdneri): the effect of experience. Journal of the Fisheries Research Board of Canada 28, 1847-1852. 